\title{
El diseño de sonido yla genealogía de su materialidad no cosificable
}

GUSTAVO COSTANTINI, UNIVERSIDAD DE BUENOS AIRES-UNIVERSIDAD NACIONAL DE LAS ARTES, ARGENTINA

Fecha de recepción: septiembre de 2015

Fecha de aceptación: noviembre de 2015

RESUMEN: La mayoría de las teorías del diseño coinciden en que hay diseño cuando hay un resultado material, un objeto que es el diseñado. Por lo tanto, el sonido no podría considerarse como diseño, puesto que no es manipulable como una cosa. Este artículo propone revisar esta noción a partir de entender el sonido como una materialidad no cosificable, y así responder a todas las características que plantean las teorías. La materialidad comienza a considerarse en el campo de la música a través de la exploración del timbre, y de ahí surgen en el siglo XX otras propuestas que se extienden al campo del diseño de sonido, en particular en el audiovisual.

PALABRASCLAVE: Sonido, diseño, materialidad, objeto sonoro, diseño de sonido, timbre.

\begin{abstract}
Most theories of design agree that we can speak of design when there is a material result, an object that is designed. Therefore, Sound could not be considered as design since it is not subjected to manipulations like a thing. This paperproposes a revision of these notions from a point of view that understands sound as a material that is not considered as a thing, and by these means responding to all characteristics proposed by main theories. Materiality in sound begins with music through timbre explorations, and from that point we arrive to XX Century several propositions that are extended to the sound design field, in particular, the in the audiovisual domain.
\end{abstract}

KEYWORDS: Sound, design, phisicality, sound object, sound design, tone. 


\section{INTRODUCCIÓN}

El propósito de este trabajo es trazar una genealogía de una noción de materialidad de lo sonoro que permite arribar al diseño de sonido, entendiéndolo -como todo diseño- como el trabajo realizado sobre un material que propone soluciones materiales sobre un producto también material. El problema que justamente presenta el diseño de sonido-aunquetambién el diseño audiovisual, el cine y otras manifestaciones que presentan una emergencia industrial y que atraviesan etapas de proceso y producto- es lo elusivo de su condición material. Sin embargo, puede considerarse que la dificultad radica en la imposibilidad de pensar al sonido como una cosa, a diferencia de los otros diseños, cuyos productos detentan claramente su carácter tangible y manejable.

El sonido es un objeto de nuestra percepción, yla condición de objeto sonoro ya ha sido trabajada en diversas oportunidades, sobre todo en los aportes de PierreSchaeffer, Christian Metz, François Bayle y Michel Chion, entre los estudios franceses sobre acusmática y aculogía, y por Peter Strawson (1989)-quien ha delimitado el estatuto lógico de los sonidos y ha abierto el camino hacia el análisis filosófico de lo sonoro- y por Roger Scruton (1997) dentro de la filosofía anglosajona del lenguaje. Este objeto presenta una dimensión material, pero esa materialidad es de una naturaleza no cosificable. De la emergencia de una reflexión sobre esa materialidad en la música y sobre cómo ésta ha derivado en la problemática de la materialidad de lo sonoro en general -que permite diseñar el sonido- trata esta aproximación que proponemos.

\section{LA MÚSICA COMO ESTRUCTURA, GESTO Y MATERIA}

En diversas clases, textos y conferencias, el compositor Francisco Kröpfl (2005) ha planteado un abordaje singular de la música del siglo XX (pero extensible, creemos, a la más abarcadora noción de música contemporánea). En lugar de hablar de melodía, armonía, ritmo, etc., Kröpfl prefiere plantear el análisis de las obras como una tensión entre tres aspectos: estructura, gesto y materia. Se entiende por estructura al tejido de relaciones entre los sonidos tanto en sucesión como en simultaneidad, y la presencia de un principio de construcción que articule dichas relaciones. Esta noción se vuelve muy clara cuando se estudian obras dodecafónicas o seriales, dondela presencia de series de alturas, de ataques, intensidades, valores rítmicos y hasta timbres, organiza la totalidad del material musical y le brinda una sólida lógica interna, la que entendemos por su estructura. El gesto, en cambio, refiere a las dimensiones estilísticas que pueden leerse como intenciones o actitudes a las que apunta la composición, y que postulan también una aproximación a la escucha. Habrá entonces gestos que remiten a lo expresionista, impresionista, abstracto, minimalista, al estatismo, a variaciones súbitas de dinámica, a lo agresivo, a lo pasivo. Finalmente, arribamosala materia. ¿A quérefiere este aspecto? ¿En quésentido tienen los sonidos materia o qué tipo de materia es la que detentan? 


\section{MATERIA SONORA, TIMBRE Y SENSACIÓN DE MATERIALIDAD}

La materia sonora es la sensación de materialidad a la que remiten los sonidos a partir del timbre. Noción compleja si las hay, el timbre es un aspecto multidimensional que nos permite diferenciar e identificar a las distintas fuentes sonoras. Es parte del timbre el espectro de frecuencias (componentes espectrales) que forman parte de un sonido determinado. Si esos componentes espectrales están en una relación de múltiplos enteros de la frecuencia fundamental, entonces estaremos frente a un sonido de altura determinada. Si esas frecuencias no se encuentran comprendidas por ninguna relación proporcional, estaremos frente a un ruido. Pero los sonidos de altura determinada también presentan componentes de ruido, como por ejemplo sucede con una flauta travesera, cuyo soplido característico es inescindible de su identidad. La presencia de muchos armónicos o componentes espectrales (que no estén en relación armónica o de múltiplos de la frecuencia fundamental) puede indicar lo que sinestésicamente se comprende como el "brillo" de un sonido, más allá de que se trate de un sonido de altura determinada o indeterminada. Por ejemplo, el sonido de un pequeño platillo es un muy rico componente espectral y lo percibimos como muy brillante. Esto también ocurre con ciertas articulaciones de los instrumentos de cuerda o con ciertos vientos de metal, mientras que percibiremos como más opacos o menos brillantes a otras formas de ejecución de las cuerdas, a los tambores (en comparación con los platillos) y a algunos instrumentos de madera.

Además de los componentes espectrales y los componentes de ruido, también es parte del timbre la evolución de la dinámica de cada sonido a lo largo del tiempo. Este aspecto, denominado envolvente dinámica, consiste en lo que ocurre con la sonoridad de esa fuente sonora en cada sonido emitido. El primer momento, denominado ataque, es lo que media entrela articulación del sonido y la máxima intensidad alcanzada por dicha articulación; a esto sobreviene un segundo momento, que es el decay o decaimiento, lo que sucede en el momento de máxima intensidad hasta el punto de estabilización del sonido; ese momento de estabilización del sonido o cuerpo del sonido es lo que se denomina sustain o sostenimiento; finalmente, la última parte de las envolventes consiste en el release o liberación del sonido, que es la parte en la que ya no hay articulación del sonido (por ejemplo, la tecla de un piano es soltada) y se percibe la forma en la que el sonido se extingue.

Las envolventes a veces son más importantes para diferenciar un sonido de otro, más que otros aspectos, dado que generalmente en el momento del ataque de un sonido (lo que ocurre en los primeros 40 milisegundos de la articulación del sonido) se encuentra la información más importante para identificar una fuente o reconocerla respecto de otra. Si a un sonido de un piano, de una guitarra y de un arpa le quitamos el ataque y sólo nos concentramos en el sustain y el release, nos será muy difícil diferenciarlo. Pero si atendemos al ataque de 
cada uno de ellos entenderemos como muy distintos el tañido de la cuerda del arpa, de la pulsación de la cuerda de guitarra y la ejecución de la tecla del piano (cuyos martillos golpean cuerdas igualmente suspendidas y semejantes a las del arpa y en menor medida a las de la guitarra).

Las viejas definiciones de timbre se planteaban siempre de manera negativa: el timbre es lo que no era la intensidad ni la altura del sonido (más allá de la duración). Dos sonidos de igual altura e intensidad sólo podían ser diferenciados a partir del timbre. Esta dificultad para definir el timbre de manera positiva reflejaba su complejidady también cierta desconsideración teórica por su relevancia.

\section{EVOLUCIÓN HISTÓRICA DE LA MATERIA SONORA}

En la música antigua, sólo algunos cronistas nos describen la sonoridad de ciertas flautas y liras, mayormente recurriendo al efecto emotivo producido sin considerar demasiado el aspecto tímbrico o material. En la Edad Media, el dominio casi absoluto de las voces y de la música sacra, puso en el centro al don divino de la voz y del texto (entendiéndose como la Palabra) y desdeñó lo tímbrico, quedando solamente presente en la música secular y profana. En el Renacimiento, también la voz fue dominante -al menos en lo sacro y académico-y los instrumentos eran entendidos como un medio para la demostración del virtuosismo del ejecutante, no tanto por la búsqueda de sonoridades y timbres diferentes. Sin embargo, en la música medieval y en la renacentista vocal el efecto de las voces con la reverberación del espacio de las iglesias constituía la búsqueda de un efecto material acompañado por la altura de los vitrales y la filtración de una luz sagrada que auspiciaba imaginar la presencia de lo divino por encima de los feligreses. La flotación del ritmo libre del canto gregoriano reverberando en ese espacio sagrado o las complejas polifonías vocales renacentistas resonando en las catedrales eran formas también de una búsqueda de un efecto material, aun cuando la importancia estaba dada en la fuente sonora provista por la Creación (la voz humana) y por la transmisión del Verbo encontrado en las Escrituras.

Ya en la transición delaEdad Media al Renacimiento comienza tenuemente una búsqueda material a partir delos constructores deórganos. La idea defabricar un instrumento que a través de las distintas combinatorias de sus tubos y del aire circulante por ellos (regulados por diversos dispositivos) pudiesen emular a distintas fuentes sonoras, es el comienzo de una preocupación por la síntesis de la materia sonora que evolucionará durantelos siglos que siguieron. La complejidad de los órganos y los diversos problemas acústicos y físicos que depara su construcción fueron el estímulo inicial para una reflexión sobre la naturaleza de los sonidos y la obtención, en consecuencia, de su posible imitación. Pero aun cuando esto estará presente durante el período Barroco y el Clásico, el centro de atención seguirá estando en el dominio de las alturas: melodía y armonía 
serán las preocupaciones primordiales de los compositores durante los siglos XVII y XVIII (y hasta comienzos del XIX). Esto explica, por ejemplo, que Bach haya realizado tantas transcripciones de obras suyas de un instrumento a otro: conciertos para violín eran rápidamente convertidos en conciertos para clave, y partituras para cuerdas podían ser repensadas rápidamente para teclado o para instrumentos de viento (en tanto y en cuanto la agilidad de ejecución de los instrumentos así lo permitiese).

La racionalización de la música acaecida en la Ilustración y las nuevas teorizaciones de la Armonía, acentúan aún más la problemática de la música en el reino de las notas. De todas maneras, habrá ciertos intentos en el Barroco y en el Clasicismo de una búsqueda incipiente de lo material e incluso espacial: la disposición de instrumentos de viento de madera y metal en distintos puntos espaciales de la iglesia le dará a Giovanni Gabrieli un resultado interesante, aprovechando la resonancia de los espacios de las iglesias venecianas en la transición entre el Renacimiento y el Barroco. Mozart eliminará las flautas y los oboes de las maderas de su "Misa de Réquiem" y esto le dará un color más oscuro u opaco en comparación con otras obras del género.

\section{HACIA NUEVAS FRONTERAS DE LA AUDICIÓN Y LA CONSIDERACIÓN DE LA MATERIA SONORA}

Será en el Romanticismo que comenzará una nueva concepción de lo tímbrico y que la transcripción de las obras comenzará a ser más difícil o improbable. Beethoven desarrollará una búsqueda intelectual y especulativa en su tercer y último período compositivo, que auspiciará una nueva etapa en la creación musical. El segundo movimiento de su última sonata para piano (la "Sonata nro. 32", compuesta sólo con dos movimientos) presenta un tema con variaciones basándose en una especie de coral (que Beethoven denomina arietta) y que él irá complejizando paulatinamente a partir, primero, de un desarrollo de los motivos y del juego con los modos mayor y menor. Pero a partir de una de las variaciones más avanzadas -cuando ya lo motívico había hecho bastante complejo el reconocimiento del tema inicial- Beethoven comienza a trabajar en una variación realizada a partir de la ornamentación. Lo que hasta ese momento era meramente adorno, es ahora parte estructural de la construcción, y los trinos, dobles trinos y trémolos se constituyen en el esqueleto de sonoridades -una suerte de constante rumor que parece temblar- que apenas nos permiten entender que estamos escuchando la misma armonía del tema que se está variando. Este trabajo pionero en este pensamiento más especulativo se convierte en algo esencial para la búsqueda tímbrica, porque ya no hay forma de reproducir en otra fuente lo que sólo el piano es capaz de realizar de esta manera. El concepto de estructura se empieza a interrelacionar con la materia, y éstos a su vez determinan un nuevo tipo de gesto. 
Las exploraciones de Beethoven en todos los campos (sonatas para piano, sinfonías, cuartetos de cuerda, ópera) y su pensamiento especulativo plasmado en los propios planteos de las obras que revisten las más complejas operaciones intelectuales lo convertirán en el compositor más influyente del siglo XIX. La figura de Beethoven es además oportuna en un contexto histórico particular: su obra emerge inmediatamente luego de la Revolución Francesa y coincide con el pleno desarrollo de la Estética como disciplina independiente de la Filosofía y con la relativamente nueva idea del arte por el arte. Todos los compositores del siglo recibirán su influencia: Schubert en sus sonatas, cuartetos y sinfonías, Berlioz en sus planteos orquestales, Brahms en sus sinfonías y obras para piano, Wagner en sus dramas musicales (complejizando lo orquestal de sus obras de escena con el ideal beethoveniano de vínculo de música y texto planteado en la Novena sinfonía), y sobre todo su último período compositivo se convertirá en la fuente desencadenante de muchas de las ideas que harán proliferar toda la modernidad de la música que propone el Romanticismo. Hacia fines del siglo XIX las búsquedas abrirán el camino a todos los planteos de renovación de los lenguajes, y esto conducirá a las vanguardias y a todo el universo de nuevas sonoridades del siglo XX. Los dos puntos de inflexión que pueden señalarse como responsables del quiebre son, por una parte, el planteo armónico del "Tristán" de Wagner, y por otro, la emergencia de la obra orquestal de Claude Debussy. En “Tristán e Isolda”, Wagner consuma -a través de la influencia de Beethoven y a su vez de Berlioz- varias de sus ideas principales: la melodía infinita, melodía que por su complejidad y apuntalamiento armónico parece suspenderse y perpetuarse como si se tratase de una analogía de la propia vida de los personajes que las cantan, la actualización del mito como representación de todas las fuerzas humanas y, finalmente, la inestabilidad de todo el lenguaje tonal que allana el camino hacia la abstracción y la atonalidad.

En el "Preludio a la siesta de un fauno", en "El mar", en las "Imágenes para orquesta", yen sus "Nocturnos" -además de sus obras para piano pródigas de sugestiones visuales-Debussy despliega un nuevo universo sonoro que conduce a la consolidación de la nueva materialidad sonora. El tratamiento de la orquesta que se observa sobre todo en "El mar" y en las "Imágenes para orquesta" -orquesta que se convierte en el campo de experimentación que Beethoven había iniciado y que Berlioz y Wagner desarrollaron- se centra en la exploración tímbrica y en la libertad del fluir sonoro que necesitarán de oídos completamente renovados. Debussy piensa a la orquesta no como un soporte para la ejecución de melodías y armonías complejas, sino inversamente como puras sonoridades para las cuales el tipo de melodía y armonía será el perfecto vehículo. No es que Debussy desdeñe lo melódico o armónico, sino que piensa en ello como un camino hacia la potencionalidad tímbrica que esto puede detentar. De esta manera recurre a la resurrección de viejos modos griegos y eclesiásticos, a escalas exóticas y a la escala de tonos enteros, cuyo sonido en el contexto de la obra 
contemporánea generará las condiciones para nuevas posibilidades tímbricas y materiales. La huella de Debussy pronto se podrá observar en "La consagración de la primavera" de Stravinsky (el comienzo forzado del fagot que abre el ballet parece hacerse eco del comienzo de flauta del Preludio a la siesta de un fauno, y los juegos tímbricos y rítmicos que propone reciben a su vez la influencia de la obra "Juegos" que es de 1912, año anterior al estreno de "La consagración").

\section{EL NACIMIENTO DEL OBJETO SONORO}

Esta identidad entre ciertos sonidos particulares con ciertos motivos melódico-armónico-rítmicos (en lugar de observarse un desarrollo evolutivo de los parámetros se percibe la repetición de ciertas configuraciones sonoras) lleva a la idea de objeto sonoro, cosa que se consolidará en la obra de Edgar Varèse y en la música concreta.

Varèse plantea sus obras-ya atonales-desdelo puramente materialylo melódico o armónico es una consecuencia de ello: por ejemplo, en sus obras puede plantearse la búsqueda de un sonido extremadamente grave, largo y fortísimo, que deberá ser rugoso y que a su vez tendrá una envolvente determinada (su comportamiento dinámico en función del tiempo). Finalmente, decidirá que esto lo conseguirá con trombón bajo y, por último, decidirá qué nota deberá ejecutar. Lo interesante del planteo de Varèse es que cada vez que se ejecute ese sonido, se lo hará con todas esas configuraciones. En sus composiciones aparecen materiales claramente acotados -aun cuando la obra sea muy compleja-y de esta manera escuchamos que hay más que notas, configuraciones sonoras donde la nota elegida está asociada a una duración determinada, a un color, un gesto, una envolvente, etc. Podríamos decir que una de sus obras podría estar constituida por tres sonidos de flauta (uno alto, largo y con mucho soplido y suave, otro grave, corto y extremadamente fuerte, y otro medio, fuerte, largo y rugoso), y no por distintas notas tocando distintas articulaciones. Esta presencia de combinatorias materiales hace que el oyente se familiarice con estos objetos sonoros que pasan a constituirse en los materiales de construcción, como si se tratase propiamente de una tectónica hecha de sonidos.

Esta idea de objeto sonoro en Varèse tendrá un correlato en el pensamiento de Pierre Schaeffer ${ }^{1}$ creador y pionero de nuevas disciplinas (como la Acusmática y la Aculogía) y autor de una de las más completas y complejas taxonomías de los sonidos posibles, su Tratado de los objetos musicales, pero también en el desarrollo de un nuevo tipo de composición, que es el producido en la música concreta. Schaeffer retoma el concepto griego de akousmaticos (lo que se escucha pero cuya fuente no se ve) y lo convierte en una disciplina que se ocupará de la descripción de lo que suena prescindiendo de la consideración de la fuente.

1 Para una indagación de las implicancias del pensamiento de Schaeffer en la música del siglo XX, véase el volumen colectivo Oü̈r, entendre, comprendre, écouter, après Schaeffer consignado en la bibliografía. 
Este estudio del sonido en sí mismo tendrá como consecuencia la clasificación más completa en cuanto a dar cuenta de todos los tipos de sonidos posibles, tanto para la música como para cualquier práctica sonora. Es allí donde fundamenta teóricamente la posibilidad del objeto sonoro y donde da cuenta de todos los elementos a considerar para hablar de la materia sonora. La música concreta es, a su vez, una práctica en la que la composición consiste en la fijación de sonidos grabados y procesados en una especie de sonomontaje realizado originalmente en una cinta magnetofónica (hoy puede realizarse en un disco rígido o cualquier otro soporte analógico o digital en el cual el sonido esté fijado).

En estas obras, Schaeffer recurre a notas musicales tomadas de obras preexistentes, a ruidos, a voces y a cualquier tipo de material heterogéneo cuyo interés radica en lo que cada sonido constituye como objeto sonoro fijado y apreciado en todas sus dimensiones materiales. En algunas de sus piezas, Schaeffer trabaja sobre la alteración a través de procesamientos electrónicos de notas de piano, pero en otras a partir de ruidos, como por ejemplo sonidos de trenes. Lo que antes era efímero e imposible de asir, se convierte en objeto a partir de su fijación en un soporte grabado. Esta transformación permite apreciar aquello que otrora era desconsiderado como algo aleatorio o accidental (el ruido) y lo pone en el centro de nuestra escucha para convertirlo en un material estético interesante. El ruido ya no es un mero accidente de las cosas, sino un objeto acústico que se nos ofrece para una nueva consideración.

PierreHenryescribe un ballet concretotitulado "Variaciones para una puerta y un suspiro", basado en el sonido grabado y fijado del ruido de una puerta de un granero cuyos crujidos se convierten en toda una gama de sonoridades que ahora ocupan lo que antes era ocupado por melodías y armonías. La música concreta se convierte en la plataforma para una nueva escucha sobre el ruido y sobre la materialidad del sonido. Es más, pone a la materialidad en el centro de la escena.

\section{MATERIALIDAD NO COSIFICABLE}

¿Pero es ésta una materialidad equivalente a la materialidad de las cosas? En su profundo trabajo sobre el sonido en todas sus facetas, Michel Chion (2000) le dedica un capítulo al problema del sonido como lo incosificable. Allí plantea diversas cuestiones entre las cuales destaca la dificultad de fijar al sonido entre una causa y un efecto, el caso de ocupar el mismo espacio distintos sonidos que conforman un acorde, o suponer al sonido de algo como si se tratase de una característica más (equivalente, por ejemplo, a su color). Chion desarrolla toda una serie de considerandos para demostrar la imposibilidad de considerar al sonido como una cosa, y explica claramente la historia y las razones por las cuales incluso el lenguaje le es esquivo para fijarlo en un lugar y no verlo como tironeado por la fuente que lo produce y el resultado audible que percibe el oyente. Sin embargo, esta imposibilidad de concebirlo como una cosa no impide reparar en sus condiciones materiales. Muchas veces se han confundido estas dos cuestiones y es por 
eso que la teorización sobre el diseño muchas veces entra en conflicto con su condición de no-cosa. En diversas definiciones del diseño se plantea que el resultado del diseño debe ser una cosa. Y es allí donde el diseño audiovisual y el diseño de sonido entran en problemas. Pero a pesar de ello hemos demostrado la existencia de su dimensión material más allá de su no reducción a una cosa asible.

Por lo tanto, proponemos la noción de materialidad no cosificable o materialidad virtual, y superar la reducción a la cosa, comprendiendo en su lugar a una materialidad que es perfectamente diseñable, manejable y transformable en un producto de la mente y el trabajo del diseñador.

\section{REFERENCIAS}

AA.VV.(1999). Oür, entendre, écouter, comprendre après Schaeffer. Paris: Buchet Castel.

Adorno, Th. (2003). Filosofía dela nueva música (obra completa, volumen 12). Barcelona: Akal.

Chion, M. (2000). El sonido. Barcelona: Paidós.

Chion, M. (2000). L'Art des Sons Fixés (traducción española por Carmen Pardo: El arte de los sonidos fijados). La Mancha: Universidad de Castilla.

Chion, M. (1993). La audiovisión. Barcelona: Paidós.

Chion, M. (1985). Le son au cinéma. París: Cahiers du cinéma/Editions de l’etoile.

Kröpfl, F. (julio de 2005). La situación del oyente. Revista Encrucijadas, nro. 33, UBA.

Schaeffer, P. (1966). Tratado de los objetos musicales. Madrid: Alianza.

Scruton, R. (1997). The Aesthetics of Music. Oxford: Clarendon Press.

Strawson, P. F. (1989). Individuals (Traducción española por Alfonso García Suárez: Individuos). Londres: Routledge. Madrid: Taurus.

\section{GUSTAVO COSTANTINI}

Diseñador de sonido, editor y músico. Es profesor titular en la Carrera de Diseño de Imagen y Sonido de la Universidad de Buenos Aires y en la Universidad Nacional de las Artes. Es profesor invitado de la London Film School, de la University for Creative Arts, la University of London Royal Holloway y la National Film and Television School (Gran Bretaña), de la International Film School de Colonia (Alemania), del European Film College (Dinamarca), de la Universidad de La República y la Universidad ORT (Uruguay). Es doctorando de la Universidad de Buenos Aires y uno de sus directores de investigación es Michel Chion. Es miembro del comité editorial de The New Soundtrack (Edinburgh University Press).

E-mail:gcostantini@hotmail.com 